\title{
Outcome analysis of Phase I trial patients with metastatic KRAS and/or TP53 mutant non-small cell lung cancer
}

\author{
Yudong Wang ${ }^{1,5}$, Zhijie Wang ${ }^{1,6}$, Sarina Piha-Paul ${ }^{1}$, Filip Janku ${ }^{1}$, Vivek Subbiah ${ }^{1}$, Naiyi \\ Shi $^{1}$, Kenneth Hess ${ }^{2}$, Russell Broaddus ${ }^{3}$, Baoen Shan ${ }^{7}$, Aung Naing ${ }^{1}$, David Hong ${ }^{1}$, \\ Apostolia M. Tsimberidou ${ }^{1}$, Daniel Karp ${ }^{1}$, Charles Lu ${ }^{4}$, Vali Papadimitrakopoulou ${ }^{4}$, \\ John Heymach ${ }^{4}$, Funda Meric-Bernstam ${ }^{1}$ and Siqing Fu ${ }^{1}$ \\ ${ }^{1}$ Department of Investigational Cancer Therapeutics, The University of Texas MD Anderson Cancer Center, Houston, TX, USA \\ ${ }^{2}$ Department of Biostatistics, The University of Texas MD Anderson Cancer Center, Houston, TX, USA \\ ${ }^{3}$ Department of Pathology, The University of Texas MD Anderson Cancer Center, Houston, TX, USA \\ ${ }^{4}$ Department of Thoracic Medical Oncology, The University of Texas MD Anderson Cancer Center, Houston, TX, USA \\ ${ }^{5}$ Department of Medical Oncology, The Fourth Hospital of Hebei Medical University, Shijiazhuang, Hebei Province, People's \\ Republic of China \\ ${ }^{6}$ Department of Medical Oncology, Cancer Hospital, Chinese Academy of Medical Sciences \& Peking Union Medical College, \\ Beijing, People's Republic of China \\ ${ }^{7}$ Department of Cancer Research, The Fourth Hospital of Hebei Medical University, Shijiazhuang, Hebei Province, People's \\ Republic of China \\ Correspondence to: Siqing Fu, email: siqingfu@mdanderson.org \\ Keywords: KRAS; TP53; Phase I trial; overall survival; non-small cell lung cancer \\ Received: May 22, $2018 \quad$ Accepted: July 18, $2018 \quad$ Published: September 07, 2018 \\ Copyright: Wang et al. This is an open-access article distributed under the terms of the Creative Commons Attribution License 3.0 \\ (CC BY 3.0), which permits unrestricted use, distribution, and reproduction in any medium, provided the original author and source \\ are credited.
}

\section{ABSTRACT}

KRAS and TP53 mutations, which are the most common genetic drivers of tumorigenesis, are still considered undruggable targets. Therefore, we analyzed these genetic aberrations in metastatic non-small cell lung cancer (NSCLC) for the development of potential therapeutics. One hundred eighty-five consecutive patients with metastatic NSCLC in a phase 1 trial center were included. Their genomic aberrations, clinical characteristics, survivals, and phase 1 trial therapies were analyzed. About $10 \%, 18 \%, 36 \%$, and $36 \%$ of the patients had metastatic KRAS+ / TP53+, KRAS+ / TP53-,KRAS-/TP53+, and KRAS-/TP53- NSCLC, respectively. The most common concurrent genetic aberrations beside KRAS and/or TP53 (>5\%) were KIT, epidermal growth factor receptor, PIK3CA, C-MET, BRAF, STK11, ATM, CDKN2A, and APC. KRAS+/TP53+ NSCLC did not respond well to the phase 1 trial therapy and was associated with markedly worse progression-free (PFS) and overall (OS) survivals than the other three groups together. KRAS hotspot mutations at locations other than codon $\mathbf{G 1 2}$ were associated with considerably worse OS than those at this codon. Gene aberration-matched therapy produced prolonged PFS and so was anti-angiogenesis in patients with TP53 mutations. Introduction of the evolutionary action score system of TP53 missense mutations enabled us to identify a subgroup of NSCLC patients with low-risk mutant p53 proteins having a median OS duration of $\mathbf{6 4 . 5}$ months after initial diagnosis of metastasis. These data suggested that patients with metastatic dual KRAS+/TP53+ hotspot-mutant NSCLC had poor clinical outcomes. Further analysis identified remarkably prolonged survival in patients with low-risk mutant p53 proteins, which warrants confirmatory studies. 


\section{INTRODUCTION}

Non-small cell lung cancer (NSCLC), constituting more than $80 \%$ of all lung cancers, is the leading cause of cancer morbidity and mortality worldwide [1]. Mutations of $K R A S$, a member of the RAS family, are among the most common oncogene mutations in NSCLC patients, identified in up to $30 \%$ of NSCLC cases [2-5]; are most frequently activating point mutations at codons G12, G13, and Q61 [6]; occur most often in patients with adenocarcinoma, who are white, and who are current or former smokers [7-9]; and are mutually exclusive of epidermal growth factor receptor (EGFR) mutations and ALK and ROS1 rearrangements [8,10-12]. Inactivation of the TP53 gene is the most frequent molecular alteration in NSCLCs. Reported incidence rates for TP53 exon 5-8 mutations in NSCLC patients ranged from 31\% to $79 \%$, with mutations occurring most frequently in squamous cell carcinoma cases [13-15]. TP53 plays many important roles in the prevention and suppression of abnormal cell growth through cell-cycle arrest, apoptosis, senescence, and DNA repair and induction of drug resistance $[15,16]$. Although the prognostic or predictive value of TP53 mutations has been inconclusive in NSCLC cases [17-23], recent studies demonstrated that antiangiogenic-based therapy may be appropriate for the treatment of TP53-mutant NSCLC [24-26].

Both KRAS and TP53 mutations are considered undruggable [27]. In the present study, we reviewed the demographic characteristics and clinical outcomes of patients with metastatic NSCLC who were referred to phase 1 trial center at The University of Texas MD Anderson Cancer Center in an effort to determine the impact of KRAS and TP53 mutations on their disease for the development of potential therapeutics.

\section{RESULTS}

\section{Patient demographics}

Of the 185 consecutive patients with metastatic NSCLC referred to phase 1 trials at MD Anderson, 100 (54\%) received phase 1 clinical trial therapy. In this cohort, the median ages were 60 years (range, 26-80 years) at initial metastasis diagnosis, and 62 years (range, 27-82 years) at initial phase I clinic visit, respectively. About 28\% $(n=52)$ of the patients had KRAS hotspot mutations, and 47\% $(n=86)$ had TP53 hotspot mutations (Table 1). KRAS hotspot mutations were significantly more common in current and previous smokers than in never-smokers ( $33 \%$ versus $14 \% ; p=0.015)$, patients with adenocarcinoma than in those with squamous cell carcinoma ( $32 \%$ versus $14 \%$; $p=0.031$ ), patients who had prior surgery for tumor resection than those who did not ( $38 \%$ versus $22 \%$; $p=0.029$ ), and patients who had prior EGFR inhibition than in those who did not $(35 \%$ versus
$19 \% ; p=0.021)$. In comparison, TP53 hotspot mutations were more common in male than in female patients $(54 \%$ versus $38 \%$; $p=0.030$ ) patients without adenocarcinoma than in those with adenocarcinoma $(67 \%$ versus $41 \%$; $p=0.005)$, and in patients with poorly differentiated tumors than in those without ( $61 \%$ versus $35 \% ; p<0.001)$. No Asian patients presented with KRAS hotspot-mutant NSCLC, whereas $31 \%$ of non-Asian patients presented with it $(p=0.007)$.

\section{Concurrent $K R A S$ and TP53 hotspot mutations}

Genomic analysis of the 185 NSCLC patients revealed concurrent KRAS and TP53 hotspot mutations $(K R A S+/ T P 53+)$ in 19 patients $(10 \%)$, TP53 hotspot mutations only (KRAS-/TP53+) in 67 patients $(36 \%)$, KRAS hotspot mutations only (KRAS+/TP53-) in 33 patients (18\%), and no hotspot mutations (KRAS-/TP53-) in 66 patients (36\%). Besides KRAS and TP53 hotspot mutations, we identified KIT, EGFR, PIK3CA, c-MET, BRAF, STK11, ATM, CDKN2A, and APC hotspot mutations and/or gene variants in more than $5 \%$ of patients with metastatic NSCLC as shown in Table 2. BRAF hotspot mutations occurred more frequently in $K R A S$ /TP53- NSCLC cases than in KRAS+ and/or TP53+ cases $(p=0.006)$. None of the 52 patients with KRAS hotspot mutations had EGFR hotspot mutations, whereas 38 of the 133 patients (29\%) without KRAS mutations harbored EGFR hotspot mutations $(p<0.001)$.

\section{The impact of KRAS and TP53 hotspot mutations on survivals}

The median OS for these 185 patients were 8.9 months (95\% confidence interval [CI], 15.7-23.4 months) from initial phase I clinic visit, and 25.9 months (95\% CI, 14.3-41.5 months) from initial metastasis diagnosis, respectively. Our results showed that the median OS from initial phase I clinic visit was significantly longer in patients who had good RMH prognostic scores of 0-1 $(\mathrm{n}=138 ; 10.7$ months, $95 \% \mathrm{CI}, 8.3-13.2$ months) than those who had poor RMH prognostic scores of $2-3$ ( $n=47 ; 4.6$ months, 95\%CI, 3.1-6.2 months; $p<0.001$ ). The MDACC prognostic score system was also validated in these patients: scores of $0-1$ ( $\mathrm{n}=121 ; 11.5$ months, $95 \% \mathrm{CI}$, 9.114 months), scores of 2 ( $\mathrm{n}=45 ; 5$ months, $95 \%$ CI, 3.7-6.4 months), and scores of $>2(\mathrm{n}=19 ; 1.8$ months, $95 \% \mathrm{CI}$, $1-2.6$ months; $p<0.001$ ), respectively.

Survival analysis demonstrated that 19 patients with metastatic KRAS+/TP53+ NSCLC had a median OS of 19.5 months (95\% CI, 15.7-23.4 months) from initial metastasis diagnosis and 7 months $(95 \%$ CI, 2.1-12 months) from initial phase I clinic visit. In comparison, the median OS were 27.9 months (95\% CI, 14.3-41.5 months) and 8.5 months (95\% CI, 3.8-13.1 months) in KRAS+/TP53-, 28.2 months (95\% CI, 18.5-37.9 months) 
Table 1: Patient characteristics per $K R A S$ and/or TP53 hotspot mutation status

\begin{tabular}{|c|c|c|c|c|c|}
\hline Parameters & $\begin{array}{c}\text { Total } \\
\text { N = 185 (\%) }\end{array}$ & $\begin{array}{c}K R A S+/ T P 53+ \\
\mathrm{N}=19(\%)\end{array}$ & $\begin{array}{c}\text { KRAS-/TP53+ } \\
\mathrm{N}=67(\%)\end{array}$ & $\begin{array}{c}K R A S+/ T P 53- \\
\mathrm{N}=33(\%)\end{array}$ & $\begin{array}{c}\text { KRAS-/TP53- } \\
\mathrm{N}=66(\%)\end{array}$ \\
\hline \multicolumn{6}{|l|}{ Gender } \\
\hline Male & $96(52)$ & $11(58)$ & $41(61)$ & $16(49)$ & $28(42)$ \\
\hline Female & $89(48)$ & $8(42)$ & $26(39)$ & $17(51)$ & $38(58)$ \\
\hline \multicolumn{6}{|l|}{ Race } \\
\hline White & $145(78)$ & $15(78)$ & $50(75)$ & $30(91)$ & $50(76)$ \\
\hline Asian & $16(9)$ & $0(0)$ & $11(16)$ & $0(0)$ & $5(7)$ \\
\hline Black & $13(7)$ & $2(11)$ & $2(3)$ & $2(6)$ & $7(11)$ \\
\hline Hispanic & $11(6)$ & $2(11)$ & $4(6)$ & $1(3)$ & $4(6)$ \\
\hline Never Smoker & $49(27)$ & $3(16)$ & $18(27)$ & $4(12)$ & $24(36)$ \\
\hline \multicolumn{6}{|l|}{ Pathology } \\
\hline Adenocarcinoma & $143(77)$ & $15(79)$ & $43(64)$ & $31(94)$ & $54(82)$ \\
\hline Squamous cell & $29(16)$ & $3(16)$ & $16(24)$ & $1(3)$ & $9(14)$ \\
\hline Others & $13(7)$ & $1(5)$ & $8(12)$ & $1(3)$ & $3(4)$ \\
\hline Phase I trial therapy & $100(54)$ & $13(68)$ & $32(48)$ & $17(52)$ & $38(58)$ \\
\hline \multicolumn{6}{|l|}{ ECOG performance } \\
\hline 0 & $2(1)$ & $1(5)$ & $0(0)$ & $0(0)$ & $1(2)$ \\
\hline 1 & $135(73)$ & $15(79)$ & $43(64)$ & $25(76)$ & $52(78)$ \\
\hline 2 & $34(18)$ & $3(16)$ & $20(30)$ & $3(9)$ & $8(12)$ \\
\hline 3 & $14(8)$ & $0(0)$ & $4(6)$ & $5(15)$ & $5(8)$ \\
\hline \multicolumn{6}{|l|}{ BMI } \\
\hline $\mathrm{BMI}<18.5$ & $20(11)$ & $1(5)$ & $7(10)$ & $2(6)$ & $10(15)$ \\
\hline $18.5 \leq \mathrm{BMI}<24$ & $78(42)$ & $10(53)$ & $29(43)$ & $15(46)$ & $24(36)$ \\
\hline $24 \leq \mathrm{BMI}<27$ & $35(19)$ & $4(21)$ & $13(20)$ & $7(21)$ & $11(17)$ \\
\hline $\mathrm{BMI} \geq 27$ & $52(28)$ & $4(21)$ & $18(27)$ & $9(27)$ & $21(32)$ \\
\hline Prior Surgery & $69(37)$ & $9(47)$ & $24(36)$ & $17(52)$ & $19(29)$ \\
\hline Prior Radiation & $132(71)$ & $13(68)$ & $47(70)$ & $25(76)$ & $47(71)$ \\
\hline Prior VEGF inhibition & $54(29)$ & $6(32)$ & $17(25)$ & $10(30)$ & $21(32)$ \\
\hline Prior EGFR inhibition & $83(45)$ & $3(16)$ & $32(48)$ & $13(39)$ & $35(53)$ \\
\hline Prior systemic treatmen & n number, rang & $2(0-8)$ & & & \\
\hline
\end{tabular}

Abbreviations: N, number; +, positive hotspot mutation test; -, negative hotspot mutation test; ECOG, East Collaborative Oncology Group; BMI, body mass index, VEGF, vascular endothelial growth factor, and EGFR, epidermal growth factor receptor.

and 8.9 months (95\% CI, 4.6-13.3 months) in KRAS/TP53+, and 27.2 months (95\% CI, 22.3-32.1 months) and 9.3 months (95\% CI, 4.9-13.6 months) in KRAS-/TP53cases, respectively ( $p=0.88$, and $p=0.81$ ) (Figure $1 \mathrm{~A})$. Furthermore, the 52 patients with KRAS hotspot-mutant NSCLC had a median OS of 24.3 months (95\% CI, 15.932.7 months) from initial metastasis diagnosis and 7.2 months (95\% CI, 3.3-11.2 months) from initial phase I clinic visit, whereas those without KRAS mutations had a median OS of 27.2 months (95\% CI, 22.3-32.1 months; $p=0.9$ ) and 9.2 months (95\% CI, 5.9-12.5 months; $p=0.48$ ). Similarly, patients with TP53 hotspot mutations had a median OS of 24.1 months (95\% CI, 16.7-31.6 months) and 7.7 months (95\% CI, 3.9-11.5 months), whereas those 
Table 2: The concurrent hotspot mutation / gene variant status

\begin{tabular}{|c|c|c|c|c|c|}
\hline Parameters & $\begin{array}{c}\text { Total } \\
\mathrm{N}=\mathbf{1 8 5}(\%)\end{array}$ & $\begin{array}{c}\text { KRAS+/TP53+ } \\
\mathrm{N}=19(\%)\end{array}$ & $\begin{array}{c}\text { KRAS-/TP53+ } \\
\mathrm{N}=67(\%)\end{array}$ & $\begin{array}{c}\text { KRAS+/TP53- } \\
\mathrm{N}=33(\%)\end{array}$ & $\begin{array}{c}\text { KRAS-/TP53- } \\
\mathrm{N}=66(\%)\end{array}$ \\
\hline KIT & $58(30.8)$ & $11(19)$ & $16(27.6)$ & $12(20.7)$ & $19(32.7)$ \\
\hline EGFR & $38(20.5)$ & 0 & $15(39.5)$ & 0 & $23(60.5)$ \\
\hline PIK3CA & $27(14.1)$ & $2(7.4)$ & $10(37.1)$ & $6(22.2)$ & $9(33.3)$ \\
\hline c-MET & $22(11.4)$ & $2(9.1)$ & $4(18.2)$ & $3(13.6)$ & $13(59.1)$ \\
\hline BRAF & $16(8.7)$ & $1(6.3)$ & $3(18.7)$ & $1(6.3)$ & $11(68.7)$ \\
\hline STK11 & $16(8.7)$ & $2(12.5)$ & $4(25)$ & $4(25)$ & $6(37.5)$ \\
\hline ATM & $15(8.1)$ & 0 & $4(26.7)$ & $6(40)$ & $5(33.3)$ \\
\hline CDKN2A & $12(6.5)$ & $1(8.3)$ & $6(50)$ & $2(16.7)$ & $3(25)$ \\
\hline APC & $10(5.4)$ & $1(10)$ & $6(60)$ & 0 & $3(30)$ \\
\hline KDR & $7(3.8)$ & 0 & $2(28.6)$ & $2(28.6)$ & $3(42.8)$ \\
\hline CTNNB1 & $6(3.2)$ & 0 & $3(50)$ & 0 & $3(50)$ \\
\hline SMO & $5(2.7)$ & $2(40)$ & $2(40)$ & 0 & $1(20)$ \\
\hline FBXW7 & $5(2.7)$ & 0 & $2(40)$ & 0 & $3(60)$ \\
\hline ERBB2 & $4(2.2)$ & 0 & $2(50)$ & 0 & $2(50)$ \\
\hline ERBB4 & $4(2.2)$ & $1(25)$ & $2(50)$ & 0 & $1(25)$ \\
\hline IDH1 & $4(2.2)$ & $2(10.5)$ & 0 & $1(3)$ & $1(1.5)$ \\
\hline SMAD4 & $4(2.2)$ & 0 & $2(50)$ & 0 & $2(50)$ \\
\hline FGFR3 & $4(2.2)$ & 0 & $4(50)$ & 0 & 0 \\
\hline FGFR2 & $3(1.6)$ & 0 & $3(100)$ & 0 & 0 \\
\hline AKT1 & $3(1.6)$ & $1(33.3)$ & $1(33.3)$ & 0 & $1(33.3)$ \\
\hline JAK3 & $3(1.6)$ & 0 & $1(33.3)$ & $1(33.3)$ & $1(33.3)$ \\
\hline NOTCH1 & $3(1.6)$ & 0 & $1(33.3)$ & $2(66.7)$ & 0 \\
\hline PDGFRA & $3(1.6)$ & 0 & $2(66.7)$ & 0 & $1(33.3)$ \\
\hline FGFR1 & $2(1.1)$ & $1(50)$ & 0 & 0 & $1(50)$ \\
\hline GNAS & $2(1.1)$ & 0 & 0 & $1(50)$ & $1(50)$ \\
\hline NRAS & $2(1.1)$ & 0 & $2(100)$ & 0 & 0 \\
\hline ABL1 & $2(1.1)$ & $1(50)$ & 0 & 0 & $1(50)$ \\
\hline RET $^{*}$ & $2(1.1)$ & 0 & $2(100)$ & 0 & 0 \\
\hline $\mathrm{ALK}^{*}$ & $1(0.5)$ & 0 & 0 & $1(100)$ & 0 \\
\hline HNF1A & $1(0.5)$ & $1(100)$ & 0 & 0 & 0 \\
\hline MLH1 & $1(0.5)$ & 0 & $1(100)$ & 0 & 0 \\
\hline RB1 & $1(0.5)$ & 0 & 0 & 0 & $1(100)$ \\
\hline
\end{tabular}

Abbreviations: $\mathrm{N}$, number; + , positive hotspot mutation test; -, negative hotspot mutation test; and ${ }^{*}$ indicates rearrangement of the gene.

without TP53 mutations had 27.9 months (95\% CI, 23.532.2 months; $p=0.7)$ and 9.2 months $(95 \% \mathrm{CI}, 5.5-12.8$ months; $p=0.67$ ), respectively.
We identified KRAS hotspot mutations at codons G12 ( $n=47 ; 90 \%)$, G13 ( $n=2 ; 4 \%)$, Q61 ( $n=2 ; 4 \%)$, and I36 $(n=1 ; 2 \%)$. Patients with metastatic NSCLC harboring KRAS hotspot mutations at codon G12 and those without 
KRAS hotspot mutations had similar OS (27.9 months [95\% CI, 14.2-41.5 months] versus 27.2 months [95\% CI, 22.3-32.1 months]; $p=0.63$ ) from initial metastasis diagnosis and (9.2 months [95\% CI, 5.9-12.5 months] versus 8.5 months [95\% CI, 4.2-12.8 months]; $p=0.73$ ) from initial phase I clinic visit. The two groups combined had a longer median OS than those with KRAS hotspot mutations at locations other than codon 12 (7.9 months [95\% CI, 0-17 months]; $p<0.001$ ) (Figure 2), and (4.4 months [95\% CI, 0-9.9 months]; $p=0.073)$, respectively.

We detected 67 different types of TP53 hotspot mutations, including missense, nonsense, and frameshift mutations in 86 patients. In 69 patients with TP53 hotspot missense mutations, two classes of patients were identified: high-risk EAp53 prognostic scores (EAp53HR; $n=49$ ) and low-risk EAp53 prognostic scores (EAp53LR; $n=20$ ), according to the calculated EAp53 scores. We observed a significantly longer median OS from initial metastasis diagnosis in EAp53-LR patients (64.5 months; 95\% CI, 24.4-104.6 months) than in those with EAp53HR patients (18.8 months; 95\% CI, 14.8-22.8 months; $p=0.001)$ with a hazard ration (HR) of 0.3 (95\% CI, 0.14$0.63 ; p=0.001)$ after adjustment with ECOG functional status, number of metastatic sites, and serum levels of lactate dehydrogenase and albumin; and in patients without TP53 hotspot mutations ( $n=99 ; 27.9$ months; $95 \%$ CI, 23.5-32.2 months; $p=0.043$ ) with a HR of 0.52 (95\% CI, 0.27-0.99; $p=0.049$ ) (Figure 3A). Similarly, a significant longer median OS from initial phase I clinic visit was observed in EAp53-LR patients (32 months; 95\% CI, 13.1-50.8 months) than in EAp53-HR patients (5.4 months; 95\% CI, 4.1-6.8 months; $p=0.001)$ with a HR of 0.29 (95\% CI, 0.13-0.63; $p=0.002)$, and in patients without TP53 hotspot mutations (9.2 months; 95\% CI, 5.5-12.8 months; $p=0.042)$ with a HR of $0.51(95 \% \mathrm{CI}, 0.26-0.98$; $p=0.048$ ).

In patients with concurrent $K R A S$ hotspot mutations, we did not observe an OS difference from initial metastasis diagnosis between EAp53-LR (14.8 months; 95\% CI, 5.3-24.3 months) and EAp53-HR patients (20.1 months; 95\% CI, 14.1-26.1 months; $p=0.9$ ) with a HR of 0.92 (95\%CI, 0.24-3.5; $p=0.9)$; and from initial phase I clinic visit between EAp53-LR (6.5 months; 95\% CI, 0-21.3 months) and EAp53-HR patients ( 7 months; $95 \%$ CI, 0.1-14 months; $p=0.55)$ with a HR of $0.67(95 \% \mathrm{CI}$, $0.17-2.5 ; p=0.55)$. In patients without detected $K R A S$ hotspot mutations, EAp53-LR patients had a significantly longer median OS from initial metastasis diagnosis (64.5 months; 95\% CI, 26.1-102.9 months), and from initial phase I clinic visit (32 months; 95\% CI, 20.8-43.1 months)

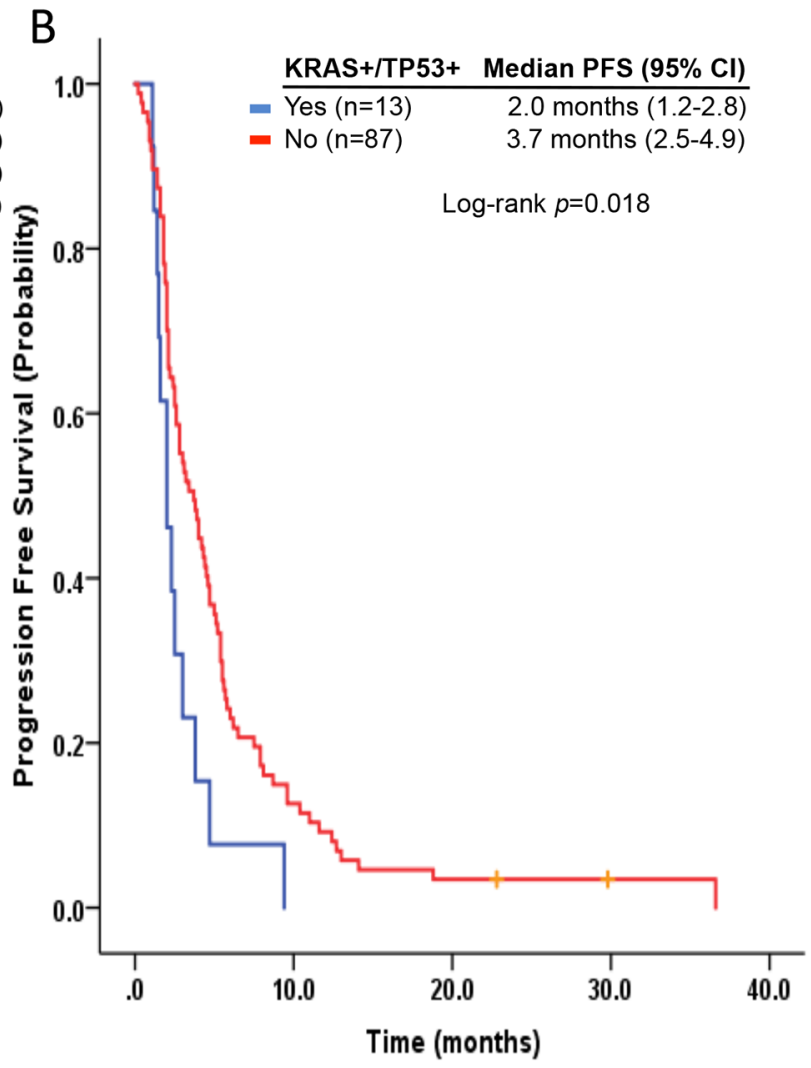

Figure 1: Kaplan-Meier curves of (A) overall survivals in patients with metastatic NSCLC according to KRAS and TP53 hotspot mutation status and (B) progression-free survivals in patients with metastatic $K R A S+/ T P 53+$ NSCLC who received phase 1 trial therapy as the firstline therapy versus those without KRAS+/TP53+ NSCLC. 

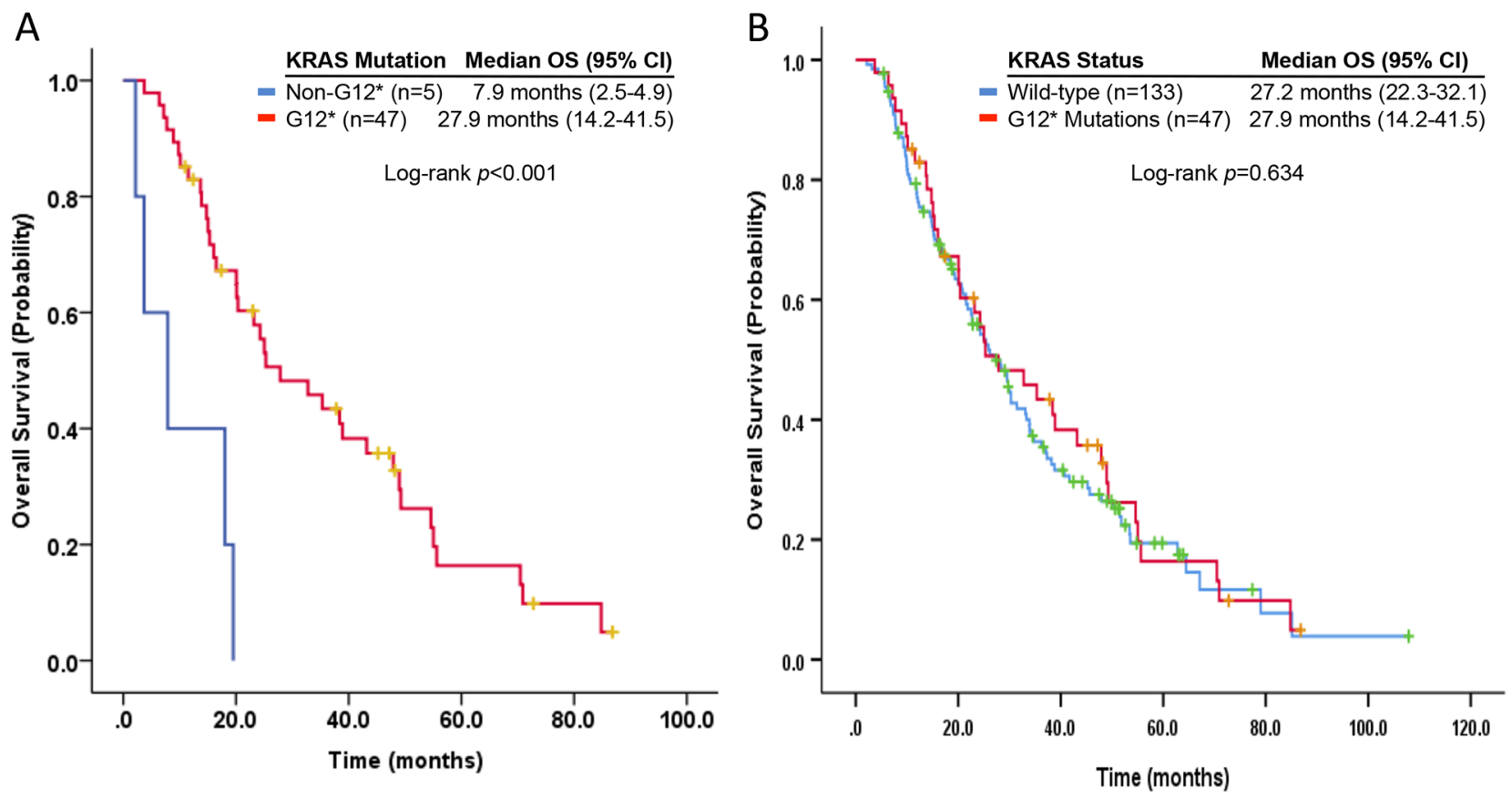

Figure 2: Kaplan-Meier curves of overall survivals in (A) patients with metastatic KRAS hotspot-mutant NSCLC (codon G12 versus non-G12) and (B) patients with KRAS hotspot mutations at codon G12 versus those without KRAS hotspot mutations.
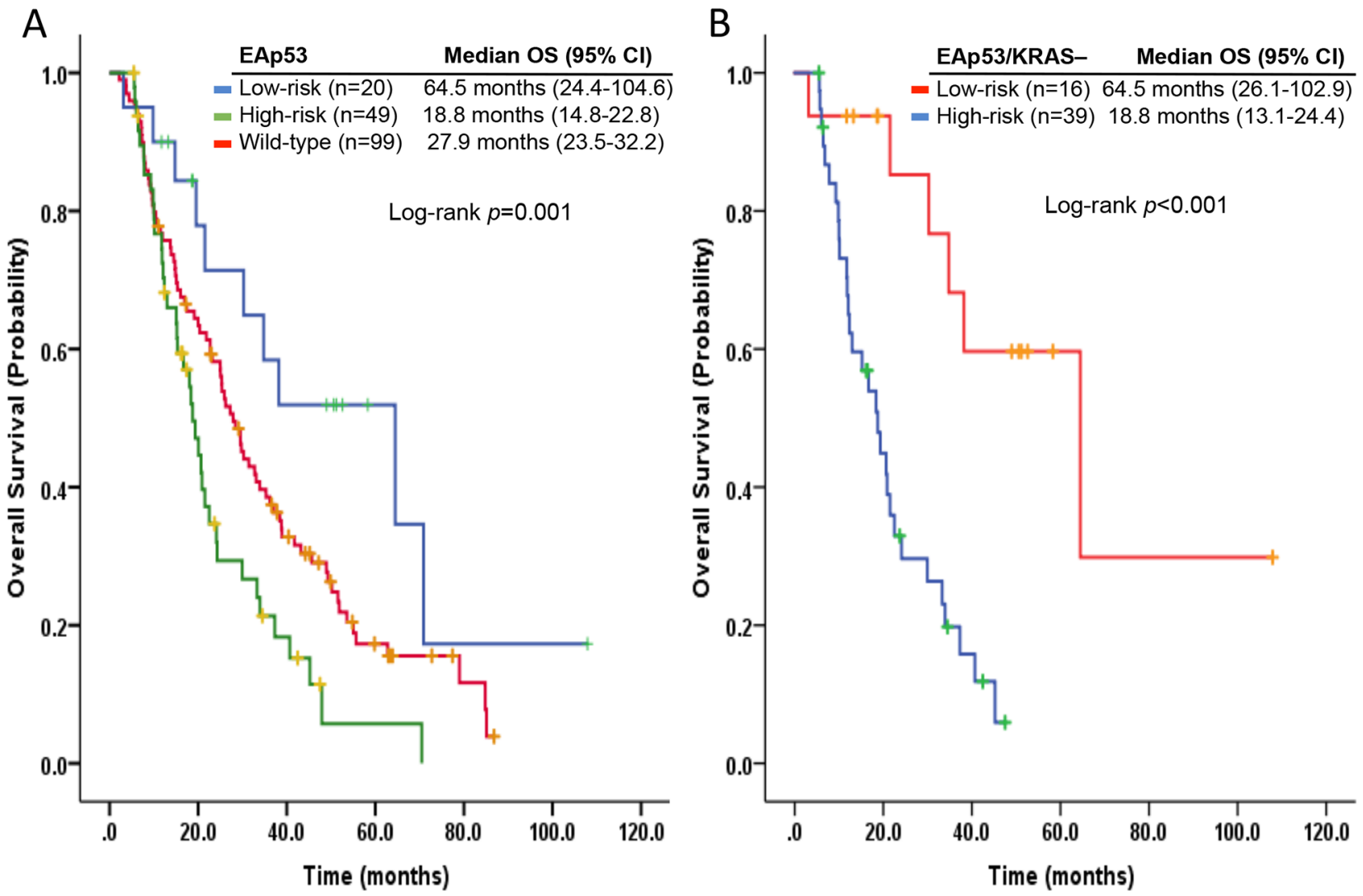

Figure 3: Kaplan-Meier curves of overall survivals according to the EAp53 scores in all patients (A) and in those without $K R A S$ hotspot mutations (B). 
than those in EAp53-HR patients (18.8 months; 95\% CI, 13.1-24.4 months; $p<0.001$ ), and (5.4 months; 95\% CI, 3.4-7.5 months; $p=0.001)$ with a HR of $0.2(95 \% \mathrm{CI}, 0.07-$ $0.51, p=0.001$ ), and 0.23 (95\% CI, 0.08-0.6, $p=0.003$ ), respectively (Figure $3 \mathrm{~B}$ ).

\section{The impact of phase 1 trial therapy on PFS}

The first-line phase 1 trial therapy led to similar median PFS in KRAS+ $(\mathrm{n}=30 ; 2.3$ months; $95 \%$ CI, $1.5-$ 3.1 months $)$ and KRAS- $(n=70 ; 3.4$ months; $95 \%$ CI, $2.3-$ 4.5 months) patients $(p=0.15)$, as well as in TP53+ $(n=45$; 2.5 months; 95\% CI, 1.6-3.4 months $)$ and TP53- $(n=55$; 3.4 months; 95\% CI, 2.3-4.5 months) patients $(p=0.3)$. $K R A S+/ T P 53+$ patients $(n=13)$ had a median PFS of 2 months (95\% CI, 1.2-2.8 months), which was significantly shorter than that in KRAS+/TP53-, KRAS-/TP53+, and $K R A S$-/TP53- patients combined ( $n=87 ; 3.7$ months; 95\% CI, 2.5-4.9 months; $p=0.018$ ) (Figure 1B). Among patients receiving antiangiogenic agent-based phase 1 trial therapy, we observed one partial response and six cases of stable disease (clinical benefit, $58.3 \%)$ in TP53+ patients $(n=12)$. Also, the TP53+ patients had a median PFS of 4.2 months (95\% CI, 0.3-8.1 months), which was significantly better than that in TP53-patients $(n=7)$ on clinical benefit $(0 \%$; $p=0.017$ ), and median PFS (2.6 months; 95\% CI, 1.3-3.9 months; $p=0.05$ ) (Figure 4A). In patients who received BRAF and/or MEK inhibitor-based phase 1 trial therapy $(n=15)$, we observed four partial responses and six cases of stable disease (clinical benefit, 83.3\%) in $12 \mathrm{BRAF}+$ or $K R A S+$ patients. Also, these patients had a median PFS of 7.9 months (95\% CI, 2.2-13.6 months). In contrast, in three BRAF- and $K R A S$ - patients, we observed one case of stable disease (clinical benefit, 33.3\%; $p=0.08$ ), and a median PFS of 1.9 months (95\% CI, 0.2-3.7 months; $p=0.015$ ) (Figure 4B).

Including TP53+ patients who received antiangiogenic therapy $(n=12), 29$ patients received matched phase 1 trial therapy: BRAF inhibition for BRAF $(n=9)$, EGFR inhibition for $\operatorname{EGFR~}(n=5: 1$ receiving combination therapy with antiangiogenic therapy), MEK inhibitors for $\operatorname{KRAS}(n=3)$, and anti-HER2 inhibition for ERBB2 $(n=1)$, leading to 1 complete response, 6 partial responses, and 12 cases of stable disease (clinical benefit, $65.5 \%$ ). In addition, these patients had a median PFS duration of 4.7 months (95\% CI, 2.9-6.5 months), which was significantly better than that in patients who did not receive matched therapy $(n=71)$ : 1 had a partial response and 22 had stable disease (clinical benefit, 32.4\%; $p=0.002$ ), and their median PFS duration was 2.6 months (95\% CI, 2.1-3.2 months; $p=0.001$ ) (Figure 4C).

\section{DISCUSSION}

We previously reported on an outcome analysis of patients with metastatic KRAS and TP53 hotspot-mutant solid tumors in a phase 1 trial center [28]. In the present study, we focused on the impact of KRAS and/or TP53 hotspot mutations on patients with metastatic NSCLC as well as the impact of phase 1 clinical trial therapy on their survival. We selected 185 consecutive patients from June 2011 to December 2016. We found that the most frequent genomic aberrations in these NSCLC patients were TP53 (47\%), KIT (31\%), KRAS (28\%), EGFR (21\%), PIK3CA (14\%), c-MET (11\%), BRAF (9\%), STK11 (9\%), ATM (8\%), CDKN2A (7\%), and APC (5\%) mutations, which were similar to previously reported genomic aberrations $[29,30]$. About $10 \%$ of the patients had KRAS+/TP53+ NSCLC, whereas $18 \%, 36 \%$, and $36 \%$ had $K R A S+/ T P 53-$, $K R A S-/ T P 53+$, and KRAS-/TP53- NSCLC, respectively. We identified $K R A S$ hotspot mutations at codon G12 $(90 \%)$ in 47 patients, and 67 different types of TP53 hotspot mutations, including missense, nonsense, and frameshift mutations in 86 patients. EGFR and $K R A S$ hotspot mutations occurred exclusively, whereas we observed BRAF hotspot mutations more frequently in $K R A S$-/TP53- patients than in KRAS+ and/or TP53+ patients as described previously [31-34].

Further analyses produced several interesting findings. First, patients with metastatic KRAS+/TP53+ NSCLC tended to have poor outcomes with a median OS of 19.5 months (95\% CI, 15.7-23.4 months), about 6.8 months shorter than those with metastatic KRAS- and/or TP53NSCLC. Consistent with this, patients with metastatic $K R A S+/ T P 53+$ NSCLC did not respond to the phase 1 trial therapy well, with a median PFS of 2 months (95\% CI, 1.22.8 months), which was significantly worse than that in KRAS+/TP53-, KRAS-/TP53+, and KRAS-/TP53-patients (3.7 months; 95\% CI, 2.5-4.9 months). These data imply that the status of KRAS and TP53 mutation in patients with metastatic NSCLC might serve as a prognostic and predictive factor. Further exploration of the concurrent mutational profiling as demonstrated in Table 2 in the setting of KRAS and/or TP53 mutation is warranted to establish their roles to predict prognosis and response in large cohorts of patients. It was noted that few patients from this retrospective cohort were enrolled in phase 1 clinical trials of immunotherapy. Thus, this finding does not apply to future patients, especially when a majority of patients are enrolled in immunotherapy-based phase 1 clinical trials.

Additionally, patients with $K R A S$ hotspot mutations at locations other than codon G12 had significantly worse OS than did patients with KRAS hotspot mutations at codon G12 and $K R A S$ - patients. This finding is consistent with our and others' previous findings that patients harboring mutations at codon G13 had significantly worse OS than did those without mutations at this codon $[28,35,36]$. This finding may enhance future drug development targeting $K R A S$ mutations to differentiate subgroups of $K R A S$-mutant NSCLC. The presence of KRAS mutations may influence the efficacy of therapy directed toward other concurrent targets or serve as a prognostic factor for survival. 
Use of the evolutionary action score system EAp53 further classified TP53 missense mutations [37, 38]. We demonstrated that the presence of low-risk TP53 mutations (EAp53-LR) was associated with significantly better OS than was that of high-risk mutations (EAp53-HR) and the absence of TP53 hotspot mutations. Of note is that patients with metastatic EAp53-LR NSCLC had a median OS longer than 5 years, indicating that the probability of dying (hazard) was reduced by $70 \%$ compared with those with metastatic EAp53-HR NSCLC ( $\mathrm{HR}=0.3 ; 95 \% \mathrm{CI}$, $0.14-0.63 ; \mathrm{p}=0.001)$, and by $48 \%$ compared with those without TP53 hotspot mutations ( $\mathrm{HR}=0.52 ; 95 \% \mathrm{CI}, 0.27$ $0.99 ; \mathrm{p}=0.049$ ). Both results were statistically significant. If this finding is confirmed in future studies, it will differentiate the concurrent consensus that TP53 mutations are associated with poor clinical outcomes in patients with metastatic NSCLC [23, 39-41]. However, the presence of $K R A S$ hotspot mutations made this survival advantage disappear in our study, suggesting the importance of concurrent mutations or genomic profiles to predicting outcomes. To the best of our knowledge, the present retrospective study is the first study of the association between TP53 mutations and survival in NSCLC patients using the EAp53 system. Future prospective large studies using this system are warranted.

Furthermore, this study demonstrated markedly greater clinical benefit and PFS with matched phase I trial therapy than with phase I trial therapy not targeting genomic aberrations. Specifically, we observed clinical benefit and PFS advantages of matched phase I clinical trial therapy targeting EGFR, BRAF, and ERBB2. However, the difference in OS between the patients who received matched and unmatched therapy was not significant, suggesting that actionable mutations are predictive factors for metastatic NSCLC and/or that more effective novel therapeutic strategies become available to these patients.

We examined potential matched therapy in patients with KRAS or TP53 hotspot mutations. Despite the limited number of patients receiving MEK inhibitor-based therapy, those with metastatic KRAS+ NSCLC tended to have better responses than did those with metastatic $K R A S$ - NSCLC. In patients with metastatic TP53 hotspot-mutant NSCLC, antiangiogenic therapy provided significantly better clinical benefit and PFS than those with TP53- NSCLC, supporting the concept that TP53 mutations induce tumor angiogenesis [24, 25, 42-44]. Further prospective studies are warranted to determine whether antiangiogenic therapy can be administered as matched therapy for metastatic NSCLC in patients with TP53 hotspot mutations, especially those EAp53-HR patients with a high EAp53 score.

Our study had some limitations. Unknown biases and patient selection influenced our analyses because this was a retrospective, single-center chart review. Also, the small number of patients limited confirmatory analyses, especially in subgroup studies. The low frequency of metastatic KRAS/TP53 hotspot-mutant NSCLC in this cohort may not reflect the real picture of NSCLC patients in society, as physicians requested genomic profiling only for patients with sufficient bone marrow, liver, and kidney function as well as decent performance function (about three quarters of the patients had an Eastern Cooperative Oncology Group score of 1 or better). Furthermore,

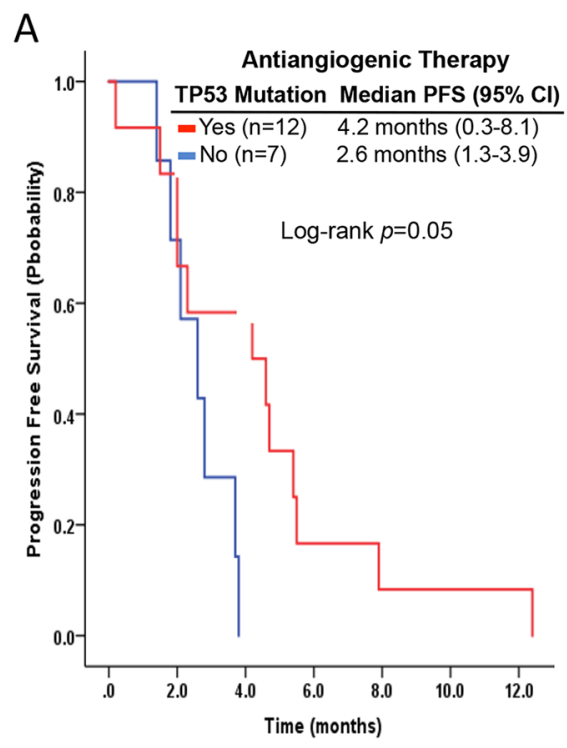

B

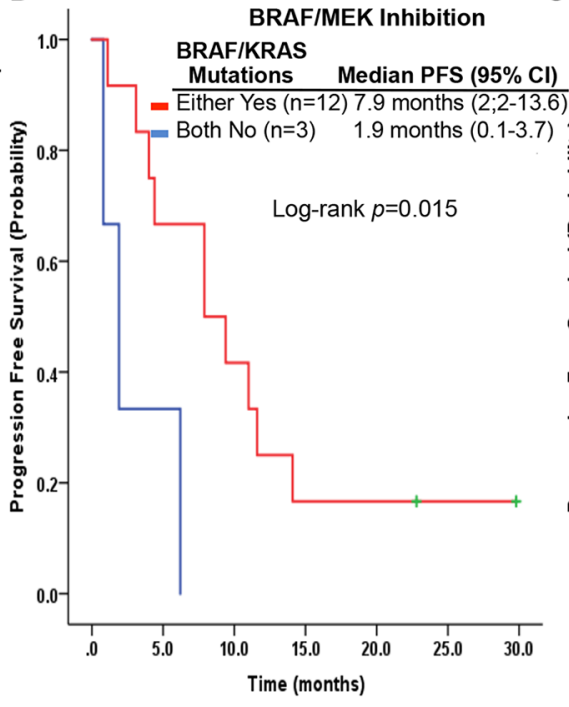

C

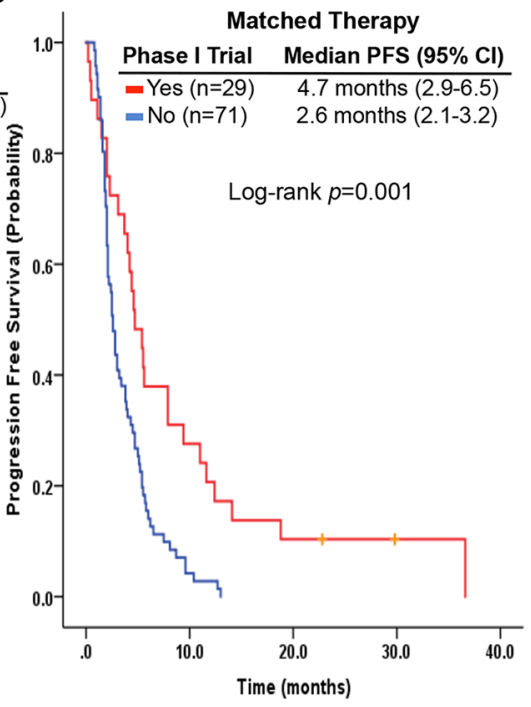

Figure 4: Kaplan-Meier curves of progression-free survivals in patients with metastatic NSCLC who received antiangiogenic phase 1 trial therapy according to TP53 hotspot mutation status (A), BRAF/MEK inhibitor-based phase 1 trial therapy according to BRAF or KRAS hotspot mutation status (B), and matched phase 1 trial therapy versus those who did not (C). 
concurrent KRAS and TP53 mutations produce potentially synergistic biological effects. NSCLC associated with both KRAS and TP53 mutations may present as a unique cancer subtype with distinct and aggressive biological behavior [45-49], resulting in many patients with metastatic KRAS+/TP53+ NSCLC not being selected for genomic profiling owing to poor functional status and organ dysfunction. We have to accept that this manuscript presents a limited set of retrospective data, which can only lead to preliminary hypotheses for future studies. Therefore, larger prospective population studies are required to further define the impact of $K R A S$ and/or TP53 mutations on patients with metastatic NSCLC.

In conclusion, our study showed that $K R A S(28 \%)$ and TP53 (47\%) hotspot mutations occurred frequently in patients with metastatic NSCLC. KRAS hotspot mutations were more common in non-Asian patients than in Asian ones, previous and current smokers than in never-smokers, and patients without EGFR and BRAF mutations than in patients with EGFR and BRAF mutations; whereas TP53 hotspot mutations were more common in male patients than in female ones, patients with squamous cell carcinoma than in those with adenocarcinoma, and patients with poorly differentiated tumors than in well differentiated tumors. Patients with metastatic KRAS+/TP53+ NSCLC $(10 \%)$ did not have good responses to phase 1 clinical trial therapy, had considerably worse PFS and tended to have worse OS than did those without these mutations. Patients with $K R A S$ hotspot mutations at the locations other than codon G12 had markedly worse survival than did those with mutations at the codon G12 and those without $K R A S$ mutations. Introduction of the EAp53 score system revealed that EAp53-LR patients with a low EAp53 score had a remarkable median OS longer than 5 years, which was significantly better than EAp53-HR patients with a high EAp53 score and those without TP53 mutations. Our data supported that the matched phase I trial therapy had greater clinical benefit and produced better PFS than did the unmatched therapy. The association of improved clinical benefit and PFS with the antiangiogenic phase I trial therapy in patients with TP53 hotspot mutations provided additional evidence that antiangiogenic agentbased phase I trial therapy is appropriate for consideration as matched therapy in patients with TP53 mutant NSCLC.

\section{MATERIALS AND METHODS}

\section{Patient selection}

From June 2011 to December 2016, 185 consecutive patients with advanced NSCLC were referred to a phase 1 trial center at MD Anderson and underwent molecular tests for genetic aberrations in their tumors. Patient demographics, medical histories, Eastern Cooperative Oncology Group performance statuses, laboratory results, gene aberration results, and outcomes of treatment administered in the phase 1 clinical trials were obtained from their electronic medical records. In accordance with the guidelines of the MD Anderson Institutional Review Board (IRB), this study was conducted under an IRBapproved protocol with waiver of informed consent.

\section{Genomic hotspot mutation and variant detection}

Next-generation sequencing was performed to detect somatic mutations in the coding sequences of a total of 46 or 50 genes [50] using the Ion AmpliSeq Cancer Hotspot Panel (Life Technologies) on the DNA extracted from the tumor samples in the Clinical Laboratory Improvement Amendments-certified Molecular Diagnostics Laboratory at MD Anderson as described previously [25, 51]. Genomic DNA from each sample was used for sequence analysis of hotspot mutations, including those at exons (codons) 2-3 (5-66) and 4 (114-150) of the KRAS gene and exons (codons) 2 (1-20), 4 (68-113), 5 (126-138), 5-6 (149-223), 7 (225-258), 8 (263-307), and 10 (332-367) of the TP53 gene.

\section{The evolutionary action score system of TP53 missense mutations}

The evolutionary action scores of TP53 missense mutations (EAp53s) were calculated based on a model of the phenotype-genotype relationship in which protein evolution was hypothesized to be a continuous and differentiable process as described previously [52-54]. The EAp53 scores ranged from 0 to 100, with higher scores representing more deleterious alterations according to an EAp53 server (http://mammoth.bcm.tmc.edu/EAp53; Baylor College of Medicine). An EAp53 threshold of 75 was selected to classify a specific mutant p53 protein as low- or high-risk (EAp53-LR and EAp53-HR, respectively) $[37,38]$.

\section{Treatment of NSCLC and survival evaluation}

The decision to enroll an eligible study patient in a phase 1 clinical trial depended on protocol availability and the discretion of the treating physician. Tumor responses to phase 1 trial therapy were evaluated according to the Response Evaluation Criteria in Solid Tumors (version 1.1) [55]. All patients were followed until death or censored on May 1, 2017. Progression-free survival (PFS) was defined as the time from study entry to the date of first objective documentation of progressive disease, date of death, or censor date. Overall survival (OS) was defined as the time from the date of the first phase 1 clinical trial visit (OS-phase I) or the date of the initial metastasis diagnosis (OS-metastasis) to the date of death or the censor date, regardless whether they received a phase I trial therapy.

The phase 1 clinical trial therapy was considered matched therapy if the patient received one or more agents 
targeting an actionable genetic aberration or proteins downstream from it, such as an EGFR inhibitor for an EGFR mutation [56], a BRAF inhibitor or a mitogenactivated protein kinase kinase (MEK) inhibitor for a BRAF mutation $[57,58]$, and crizotinib for ALK or ROS1 rearrangement $[10,11]$.

\section{Statistical analyses}

Continuous interval-scaled data were summarized using median values and ranges. Categorical data were summarized using frequencies and relative frequencies. Associations between categorical variables were tested using the chi-square and Fisher exact tests. PFS and OS curves were estimated using the Kaplan-Meier method and compared using log-rank tests. A second-order effect on hazard ratio (HR) was analyzed by Cox proportional hazards regression analysis through backwards conditional elimination, adjusted for with selected co-variables collected at initial phase I clinic visit (Eastern Cooperative Oncology Group performance status, albumin, lactate dehydrogenase, and the number of metastatic sites). All tests were two-sided and considered significant when $p$ values were less than 0.05 . Statistical analyses were performed using the SPSS software program (version 24; IBM Corporation).

\section{ACKNOWLEDGMENTS}

The authors thank the patients and the faculty and staff in the Department of Investigational Cancer Therapeutics and the Institute for Personalized Cancer Therapy at MD Anderson for their participation in phase I clinical trials and patient care; Hung Lee in the Department of Investigational Cancer Therapeutics for assistance with the patient database search; and Don Norwood in the Department of Scientific Publications at MD Anderson for assistance with editing the manuscript.

\section{CONFLICTS OF INTEREST}

No potential conflicts of interest were disclosed.

\section{REFERENCES}

1. Zhu QG, Zhang SM, Ding XX, He B, Zhang HQ. Driver genes in non-small cell lung cancer: Characteristics, detection methods, and targeted therapies. Oncotarget. 2017; 8:57680-92. https://doi.org/10.18632/oncotarget.17016.

2. Harvey JJ. An unidentified virus which causes the rapid production of tumours in mice. Nature. 1964; 204:1104-05. https://doi.org/10.1038/2041104b0.

3. Prior IA, Lewis PD, Mattos C. A comprehensive survey of Ras mutations in cancer. Cancer Res. 2012; 72:2457-67. https://doi.org/10.1158/0008-5472.CAN-11-2612.
4. Karnoub AE, Weinberg RA. Ras oncogenes: split personalities. Nat Rev Mol Cell Biol. 2008; 9:517-31. https://doi.org/10.1038/nrm2438.

5. Tomasini $\mathrm{P}$, Walia $\mathrm{P}$, Labbe $\mathrm{C}$, Jao $\mathrm{K}$, Leighl NB. Targeting the KRAS Pathway in Non-Small Cell Lung Cancer. Oncologist. 2016; 21:1450-60. https://doi.org/10.1634/theoncologist.2015-0084.

6. Rodenhuis S, van de Wetering ML, Mooi WJ, Evers SG, van Zandwijk N, Bos JL. Mutational activation of the K-ras oncogene. A possible pathogenetic factor in adenocarcinoma of the lung. $\mathrm{N}$ Engl J Med. 1987; 317:929-35. https://doi.org/10.1056/NEJM198710083171504.

7. Graziano SL, Gamble GP, Newman NB, Abbott LZ, Rooney M, Mookherjee S, Lamb ML, Kohman LJ, Poiesz BJ. Prognostic significance of K-ras codon 12 mutations in patients with resected stage I and II nonsmall-cell lung cancer. J Clin Oncol. 1999; 17:668-75. https://doi.org/10.1200/JCO.1999.17.2.668.

8. Roberts PJ, Der CJ. Targeting the Raf-MEK-ERK mitogen-activated protein kinase cascade for the treatment of cancer. Oncogene. 2007; 26:3291-310. https://doi.org/10.1038/sj.onc.1210422.

9. Riely GJ, Kris MG, Rosenbaum D, Marks J, Li A, Chitale DA, Nafa K, Riedel ER, Hsu M, Pao W, Miller VA, Ladanyi M. Frequency and distinctive spectrum of KRAS mutations in never smokers with lung adenocarcinoma. Clin Cancer Res. 2008; 14:5731-34. https://doi.org/10.1158/1078-0432.CCR-08-0646.

10. Alì G, Proietti A, Pelliccioni S, Niccoli C, Lupi C, Sensi E, Giannini R, Borrelli N, Menghi M, Chella A, Ribechini A, Cappuzzo F, Melfi F, et al. ALK rearrangement in a large series of consecutive non-small cell lung cancers: comparison between a new immunohistochemical approach and fluorescence in situ hybridization for the screening of patients eligible for crizotinib treatment. Arch Pathol Lab Med. 2014; 138:1449-58. https://doi.org/10.5858/arpa.2013-0388-OA.

11. Sholl LM, Aisner DL, Varella-Garcia M, Berry LD, Dias-Santagata D, Wistuba II, Chen H, Fujimoto J, Kugler K, Franklin WA, Iafrate AJ, Ladanyi M, Kris MG, et al, and LCMC Investigators. Multiinstitutional Oncogenic Driver Mutation Analysis in Lung Adenocarcinoma: The Lung Cancer Mutation Consortium Experience. J Thorac Oncol. 2015; 10:768-77. https://doi.org/10.1097/JTO.0000000000000516.

12. Roberts PJ, Stinchcombe TE. KRAS mutation: should we test for it, and does it matter? J Clin Oncol. 2013; 31:111221. https://doi.org/10.1200/JCO.2012.43.0454.

13. Zhang W, Edwards A, Flemington EK, Zhang K. Significant Prognostic Features and Patterns of Somatic TP53 Mutations in Human Cancers. Cancer Inform. 2017; 16:1176935117691267. https://doi.org/10.1177/1176935117691267.

14. Lee JS, Yoon A, Kalapurakal SK, Ro JY, Lee JJ, Tu N, Hittelman WN, Hong WK. Expression of p53 oncoprotein in non-small-cell lung cancer: a favorable 
prognostic factor. J Clin Oncol. 1995; 13:1893-903. https://doi.org/10.1200/JCO.1995.13.8.1893.

15. Greenblatt MS, Bennett WP, Hollstein M, Harris CC. Mutations in the p53 tumor suppressor gene: clues to cancer etiology and molecular pathogenesis. Cancer Res. 1994; 54:4855-78.

16. Muller PA, Vousden KH. Mutant p53 in cancer: new functions and therapeutic opportunities. Cancer Cell. 2014; 25:304-17. https://doi.org/10.1016/j.ccr.2014.01.021.

17. Scoccianti C, Vesin A, Martel G, Olivier M, Brambilla E, Timsit JF, Tavecchio L, Brambilla C, Field JK, Hainaut P, and European Early Lung Cancer Consortium. Prognostic value of TP53, KRAS and EGFR mutations in nonsmall cell lung cancer: the EUELC cohort. Eur Respir J. 2012; 40:177-84. https://doi.org/10.1183/09031936.00097311.

18. Ma X, Rousseau V, Sun H, Lantuejoul S, Filipits M, Pirker R, Popper H, Mendiboure J, Vataire AL, Le Chevalier T, Soria JC, Brambilla E, Dunant A, Hainaut $\mathrm{P}$, and IALT-Bio working group. Significance of TP53 mutations as predictive markers of adjuvant cisplatinbased chemotherapy in completely resected nonsmall-cell lung cancer. Mol Oncol. 2014; 8:555-64. https://doi.org/10.1016/j.molonc.2013.12.015.

19. Ma X, Le Teuff G, Lacas B, Tsao MS, Graziano S, Pignon JP, Douillard JY, Le Chevalier T, Seymour L, Filipits M, Pirker R, Jänne PA, Shepherd FA, et al, and LACE-Bio Collaborative Group. Prognostic and Predictive Effect of TP53 Mutations in Patients with Non-Small Cell Lung Cancer from Adjuvant Cisplatin-Based Therapy Randomized Trials: A LACE-Bio Pooled Analysis. J Thorac Oncol. 2016; 11:850-61. https://doi.org/10.1016/j.jtho.2016.02.002.

20. Bian C, Li Z, Xu Y, Wang J, Xu L, Shen H. Clinical outcome and expression of mutant P53, P16, and Smad4 in lung adenocarcinoma: a prospective study. World J Surg Oncol. 2015; 13:128. https://doi.org/10.1186/s12957-015-0502-0.

21. Lee SY, Jeon HS, Hwangbo Y, Jeong JY, Park JY, Lee EJ, Jin G, Shin KM, Yoo SS, Lee J, Lee EB, Cha SI, Kim CH, Park JY. The influence of TP53 mutations on the prognosis of patients with early stage non-small cell lung cancer may depend on the intratumor heterogeneity of the mutations. Mol Carcinog. 2015; 54:93-101. https://doi.org/10.1002/mc.22077.

22. Shepherd FA, Lacas B, Le Teuff G, Hainaut P, Jänne PA, Pignon JP, Le Chevalier T, Seymour L, Douillard JY, Graziano S, Brambilla E, Pirker R, Filipits M, et al, and LACE-Bio Collaborative Group. Pooled Analysis of the Prognostic and Predictive Effects of TP53 Comutation Status Combined With KRAS or EGFR Mutation in EarlyStage Resected Non-Small-Cell Lung Cancer in Four Trials of Adjuvant Chemotherapy. J Clin Oncol. 2017; 35:201827. https://doi.org/10.1200/JCO.2016.71.2893.

23. Gu J, Zhou Y, Huang L, Ou W, Wu J, Li S, Xu J, Feng J, Liu B. TP53 mutation is associated with a poor clinical outcome for non-small cell lung cancer: evidence from a meta-analysis. Mol Clin Oncol. 2016; 5:705-13. https://doi.org/10.3892/mco.2016.1057.
24. Schwaederlé $\mathrm{M}$, Lazar $\mathrm{V}$, Validire $\mathrm{P}$, Hansson J, Lacroix L, Soria JC, Pawitan Y, Kurzrock R. VEGF-A Expression Correlates with TP53 Mutations in Non-Small Cell Lung Cancer: Implications for Antiangiogenesis Therapy. Cancer Res. 2015; 75:1187-90. https://doi.org/10.1158/0008-5472.CAN-14-2305.

25. Fu S, Hou MM, Naing A, Janku F, Hess K, Zinner R, Subbiah V, Hong D, Wheler J, Piha-Paul S, Tsimberidou A, Karp D, Araujo D, et al. Phase I study of pazopanib and vorinostat: a therapeutic approach for inhibiting mutant p53-mediated angiogenesis and facilitating mutant p53 degradation. Ann Oncol. 2015; 26:1012-18. https://doi.org/10.1093/annonc/mdv066.

26. Hou MM, Wang Z, Janku F, Piha-Paul S, Naing A, Hong D, Westin S, Coleman RL, Sood AK, Tsimberidou AM, Subbiah V, Wheler J, Zinner R, et al. Continuous antiangiogenic therapy after tumor progression in patients with recurrent high-grade epithelial ovarian cancer: phase I trial experience. Oncotarget. 2016; 7:35132-43. https://doi.org/10.18632/oncotarget.9048.

27. Lazo JS, Sharlow ER. Drugging Undruggable Molecular Cancer Targets. Annu Rev Pharmacol Toxicol. 2016; 56:2340. https://doi.org/10.1146/annurev-pharmtox-010715-103440.

28. Wang Z, Piha-Paul S, Janku F, Subbiah V, Shi N, Gong J, Wathoo C, Shaw K, Hess K, Broaddus R, Naing A, Hong D, Tsimberidou AM, et al. Antiangiogenesis and gene aberration-related therapy may improve overall survival in patients with concurrent KRAS and TP53 hotspot mutant cancer. Oncotarget. 2017; 8:33796-806. https://doi.org/10.18632/oncotarget.16840.

29. Cancer Genome Atlas Research Network. Comprehensive genomic characterization of squamous cell lung cancers. Nature. 2012; 489:519-25. https://doi.org/10.1038/nature11404.

30. Collisson EA, Campbell JD, Brooks AN, Berger AH, Lee W, Chmielecki J, Beer DG, Cope L, Creighton CJ, Danilova L, Ding L, Getz G, Hammerman PS, et al, and Cancer Genome Atlas Research Network. Comprehensive molecular profiling of lung adenocarcinoma. Nature. 2014; 511:543-50. https://doi.org/10.1038/nature13385.

31. Kosaka T, Yatabe Y, Endoh H, Kuwano H, Takahashi T, Mitsudomi T. Mutations of the epidermal growth factor receptor gene in lung cancer: biological and clinical implications. Cancer Res. 2004; 64:8919-23. https://doi.org/10.1158/0008-5472.CAN-04-2818.

32. Shigematsu H, Lin L, Takahashi T, Nomura M, Suzuki M, Wistuba II, Fong KM, Lee H, Toyooka S, Shimizu N, Fujisawa T, Feng Z, Roth JA, et al. Clinical and biological features associated with epidermal growth factor receptor gene mutations in lung cancers. J Natl Cancer Inst. 2005; 97:339-46. https://doi.org/10.1093/jnci/dji055.

33. Okudela K, Woo T, Kitamura H. KRAS gene mutations in lung cancer: particulars established and issues unresolved. Pathol Int. 2010; 60:651-60. https://doi.org/10.1111/j.1440-1827.2010.02580.x. 
34. Roberts PJ, Stinchcombe TE, Der CJ, Socinski MA. Personalized medicine in non-small-cell lung cancer: is KRAS a useful marker in selecting patients for epidermal growth factor receptor-targeted therapy? J Clin Oncol. 2010; 28:4769-77. https://doi.org/10.1200/JCO.2009.27.4365.

35. Shepherd FA, Domerg C, Hainaut P, Jänne PA, Pignon JP, Graziano S, Douillard JY, Brambilla E, Le Chevalier T, Seymour L, Bourredjem A, Le Teuff G, Pirker R, et al. Pooled analysis of the prognostic and predictive effects of KRAS mutation status and KRAS mutation subtype in early-stage resected non-small-cell lung cancer in four trials of adjuvant chemotherapy. J Clin Oncol. 2013; 31:2173-81. https://doi.org/10.1200/JCO.2012.48.1390.

36. Yu HA, Sima CS, Shen R, Kass S, Gainor J, Shaw A, Hames M, Iams W, Aston J, Lovly CM, Horn L, Lydon C, Oxnard GR, et al. Prognostic impact of KRAS mutation subtypes in 677 patients with metastatic lung adenocarcinomas. J Thorac Oncol. 2015; 10:431-37. https://doi.org/10.1097/JTO.0000000000000432.

37. Neskey DM, Osman AA, Ow TJ, Katsonis P, McDonald T, Hicks SC, Hsu TK, Pickering CR, Ward A, Patel A, Yordy JS, Skinner HD, Giri U, et al. Evolutionary Action Score of TP53 Identifies High-Risk Mutations Associated with Decreased Survival and Increased Distant Metastases in Head and Neck Cancer. Cancer Res. 2015; 75:1527-36. https://doi.org/10.1158/0008-5472.CAN-14-2735.

38. Osman AA, Neskey DM, Katsonis P, Patel AA, Ward AM, Hsu TK, Hicks SC, McDonald TO, Ow TJ, Alves MO, Pickering CR, Skinner HD, Zhao M, et al. Evolutionary Action Score of TP53 Coding Variants Is Predictive of Platinum Response in Head and Neck Cancer Patients. Cancer Res. 2015; 75:1205-15. https://doi.org/10.1158/0008-5472.CAN-14-2729.

39. Kishimoto Y, Murakami Y, Shiraishi M, Hayashi K, Sekiya T. Aberrations of the p53 tumor suppressor gene in human non-small cell carcinomas of the lung. Cancer Res. 1992; 52:4799-804.

40. Tammemagi MC, McLaughlin JR, Bull SB. Metaanalyses of p53 tumor suppressor gene alterations and clinicopathological features in resected lung cancers. Cancer Epidemiol Biomarkers Prev. 1999; 8:625-34.

41. Mogi A, Kuwano H. TP53 mutations in nonsmall cell lung cancer. J Biomed Biotechnol. 2011; 2011:583929. https://doi.org/10.1155/2011/583929.

42. Ravi R, Mookerjee B, Bhujwalla ZM, Sutter CH, Artemov D, Zeng Q, Dillehay LE, Madan A, Semenza GL, Bedi A. Regulation of tumor angiogenesis by $\mathrm{p} 53$-induced degradation of hypoxia-inducible factor 1alpha. Genes Dev. 2000; 14:34-44.

43. Farhang Ghahremani M, Goossens S, Nittner D, Bisteau X, Bartunkova S, Zwolinska A, Hulpiau P, Haigh K, Haenebalcke L, Drogat B, Jochemsen A, Roger PP, Marine JC, Haigh JJ. p53 promotes VEGF expression and angiogenesis in the absence of an intact p21-Rb pathway. Cell Death Differ. 2013; 20:888-97. https://doi.org/10.1038/cdd.2013.12.

44. Said R, Hong DS, Warneke CL, Lee JJ, Wheler JJ, Janku F, Naing A, Falchook GS, Fu S, Piha-Paul S, Tsimberidou AM, Kurzrock R. P53 mutations in advanced cancers: clinical characteristics, outcomes, and correlation between progression-free survival and bevacizumabcontaining therapy. Oncotarget. 2013; 4:705-14. https://doi.org/10.18632/oncotarget.974.

45. Junttila MR, Karnezis AN, Garcia D, Madriles F, Kortlever RM, Rostker F, Brown Swigart L, Pham DM, Seo Y, Evan GI, Martins CP. Selective activation of p53-mediated tumour suppression in high-grade tumours. Nature. 2010; 468:567-71. https://doi.org/10.1038/nature09526.

46. Tan X, Carretero J, Chen Z, Zhang J, Wang Y, Chen J, Li $\mathrm{X}$, Ye H, Tang C, Cheng X, Hou N, Yang X, Wong KK. Loss of p53 attenuates the contribution of IL-6 deletion on suppressed tumor progression and extended survival in Kras-driven murine lung cancer. PLoS One. 2013; 8:e80885. https://doi.org/10.1371/journal.pone.0080885.

47. Ji H, Ramsey MR, Hayes DN, Fan C, McNamara K, Kozlowski P, Torrice C, Wu MC, Shimamura T, Perera SA, Liang MC, Cai D, Naumov GN, et al. LKB1 modulates lung cancer differentiation and metastasis. Nature. 2007; 448:807-10. https://doi.org/10.1038/nature06030.

48. Tang FH, Hsieh TH, Hsu CY, Lin HY, Long CY, Cheng KH, Tsai EM. KRAS mutation coupled with p53 loss is sufficient to induce ovarian carcinosarcomas in mice. Int $\mathrm{J}$ Cancer. 2017; 140:1860-69. https://doi.org/10.1002/ijc.30591.

49. Muzumdar MD, Dorans KJ, Chung KM, Robbins R, Tammela T, Gocheva V, Li CM, Jacks T. Clonal dynamics following p53 loss of heterozygosity in Kras-driven cancers. Nat Commun. 2016; 7:12685. https://doi.org/10.1038/ncomms12685.

50. Meric-Bernstam F, Brusco L, Shaw K, Horombe C, Kopetz S, Davies MA, Routbort M, Piha-Paul SA, Janku F, Ueno N, Hong D, De Groot J, Ravi V, et al. Feasibility of LargeScale Genomic Testing to Facilitate Enrollment Onto Genomically Matched Clinical Trials. J Clin Oncol. 2015; 33:2753-62. https://doi.org/10.1200/JCO.2014.60.4165.

51. Hou MM, Liu X, Wheler J, Naing A, Hong D, Coleman RL, Tsimberidou A, Janku F, Zinner R, Lu K, Kurzrock R, Fu S. Targeted PI3K/AKT/mTOR therapy for metastatic carcinomas of the cervix: A phase I clinical experience. Oncotarget. 2014; 5:11168-79. https://doi.org/10.18632/oncotarget.2584.

52. Lichtarge O, Bourne HR, Cohen FE. An evolutionary trace method defines binding surfaces common to protein families. J Mol Biol. 1996; 257:342-58. https://doi.org/10.1006/jmbi.1996.0167.

53. Mihalek I, Res I, Lichtarge O. A family of evolutionentropy hybrid methods for ranking protein residues by importance. J Mol Biol. 2004; 336:1265-82. https://doi.org/10.1016/j.jmb.2003.12.078. 
54. Henikoff S, Henikoff JG. Amino acid substitution matrices from protein blocks. Proc Natl Acad Sci USA. 1992; 89:10915-19. https://doi.org/10.1073/pnas.89.22.10915.

55. Eisenhauer EA, Therasse P, Bogaerts J, Schwartz LH, Sargent D, Ford R, Dancey J, Arbuck S, Gwyther S, Mooney M, Rubinstein L, Shankar L, Dodd L, et al. New response evaluation criteria in solid tumours: revised RECIST guideline (version 1.1). Eur J Cancer. 2009; 45:228-47. https://doi.org/10.1016/j.ejca.2008.10.026.

56. Tan DS, Yom SS, Tsao MS, Pass HI, Kelly K, Peled N, Yung RC, Wistuba II, Yatabe Y, Unger M, Mack PC, Wynes MW, Mitsudomi T, et al. The International Association for the
Study of Lung Cancer Consensus Statement on Optimizing Management of EGFR Mutation-Positive Non-Small Cell Lung Cancer: status in 2016. J Thorac Oncol. 2016; 11:94663. https://doi.org/10.1016/j.jtho.2016.05.008.

57. Cantwell-Dorris ER, O'Leary JJ, Sheils OM. BRAFV600E: implications for carcinogenesis and molecular therapy. Mol Cancer Ther. 2011; 10:385-94. https://doi.org/10.1158/1535-7163.MCT-10-0799.

58. Stinchcombe TE, Johnson GL. MEK inhibition in nonsmall cell lung cancer. Lung Cancer. 2014; 86:121-25. https://doi.org/10.1016/j.lungcan.2014.09.005. 